\title{
The Compositional Dependence of the Microstructure and Properties of CMSX-4 Superalloys
}

\begin{abstract}
HAO YU, WEI XU, and SYBRAND VAN DER ZWAAG
The degradation of creep resistance in Ni-based single-crystal superalloys is essentially ascribed to their microstructural evolution. Yet there is a lack of work that manages to predict (even qualitatively) the effect of alloying element concentrations on the rate of microstructural degradation. In this research, a computational model is presented to connect the rafting kinetics of Ni superalloys to their chemical composition by combining thermodynamics calculation and a modified microstructural model. To simulate the evolution of key microstructural parameters during creep, the isotropic coarsening rate and $\gamma / \gamma^{\prime}$ misfit stress are defined as composition-related parameters, and the effect of service temperature, time, and applied stress are taken into consideration. Two commercial superalloys, for which the kinetics of the rafting process are selected as the reference alloys, and the corresponding microstructural parameters are simulated and compared with experimental observations reported in the literature. The results confirm that our physical model not requiring any fitting parameters manages to predict (semiquantitatively) the microstructural parameters for different service conditions, as well as the effects of alloying element concentrations. The model can contribute to the computational design of new Ni-based superalloys.
\end{abstract}

https://doi.org/10.1007/s11661-017-4389-y

(C) The Author(s) 2017. This article is an open access publication

\section{INTRODUCTION}

THE outstanding high-temperature mechanical performance of Ni-based single-crystal superalloys, in particular, their superior creep resistance, makes them favorite materials for turbine blades in aero engines. ${ }^{[1]}$ Their interesting properties are largely dictated by the high volume fraction (up to $70 \mathrm{pct}$ ) of ordered, $\mathrm{L1}_{2}$ structured $\gamma^{\prime}$ precipitates, which are coherently embedded in a solid-solution-strengthened $\gamma$ matrix (fcc structure). During the high-temperature creep process above $900{ }^{\circ} \mathrm{C}$, the creep behavior strongly depends on the microstructural evolution. Specifically, in the early creep stage of so-called negative misfitting alloys, initially adjacent cuboidal $\gamma^{\prime}$ particles coalesce and turn into platelike structures, which are normal to the stress direction. This microstructure of alternating platelets of $\gamma$ and $\gamma^{\prime}$ phases is called the rafted structure. The

HAO YU and SYBRAND VAN DER ZWAAG are with the Novel Aerospace Materials Group, Faculty of Aerospace Engineering, Delft University of Technology, 2629 HS Delft, The Netherlands. WEI XU is with the Novel Aerospace Materials Group, Faculty of Aerospace Engineering, Delft University of Technology, and also with the State Key Laboratory of Rolling and Automation, Northeastern University, Shenyang 110819, China. Contact e-mail: xuwei@ral.neu.edu.cn Manuscript submitted July 10, 2017.

Article published online November 14, 2017 lamellar structure is rather stable and essentially blocks the dislocation bypassing mechanism, resulting in a low creep rate during the secondary creep stage. In the later stage of creep, the destabilization of the rafted microstructure occurs through a topological inversion of $\gamma / \gamma^{\prime}$ microstructure, resulting in a steep increase in the creep rate. Hence, the creep kinetics can be linked to the process of microstructural evolution, and it is of great importance to identify the main microstructural evolution mechanisms and to incorporate their effects as a function of service conditions.

The characterization of microstructural evolution during the creep process is of utmost importance in detecting the desirable mechanical properties of $\mathrm{Ni}$ single-crystalline superalloys. Hence, since the 1990s, a large number of models have been derived to describe and investigate the progress of $\gamma^{\prime}$ morphology evolution. Most of them focus on the dynamics of dislocation behavior, exploring the balance between dislocation multiplication and interaction with precipitates, as well as dislocation annihilation and recovery. ${ }^{[2-6]}$ Other models focus on probing the driving force of the anisotropic coarsening of precipitates. ${ }^{[7-10]}$ Essentially, the microstructural characteristics for $\mathrm{Ni}$ superalloys are determined by three factors: $\gamma^{\prime}$ precipitate volume fraction, isotropic coarsening, and directional coarsening, also called rafting. There are two main parameters in describing the rafted microstructure, i.e., the 
microstructural periodicity $\lambda$ and the $\gamma$ channel width $\omega$. The $\lambda$ parameter characterizes the global coarsening of the $\gamma / \gamma^{\prime}$ microstructure, since the rafted $\gamma / \gamma^{\prime}$ composite morphology is found to be almost independent of the initial microstructure. The widening of the $\gamma$ channel width, which is perpendicular to the uniaxial applied stress, is also an important process in presenting creep kinetics during microstructural evolution, since the channel width determines the dislocation motion due to the Orowan mechanism and their accumulation. The $\gamma$ channel widening is driven by the superimposition of internal misfit stress and the uniaxial applied stress, which can significantly affect the kinetics of the anisotropic coarsening mechanism.

As mentioned previously, the creep kinetics are linked to the process of microstructural evolution, which is not only a function of the imposed loading conditions but also of the chemical composition of the superalloy. However, there are only a few studies that attempt to show the effect of alloying element concentrations on microstructural evolution ${ }^{[11-13]}$ because of the large number of potential interactions between the alloying elements and the complex dependences on service temperature, time, and applied stress that need to be evaluated. Theoretical analyses and computer modeling tools might conceivably provide a qualitative or semiquantitative method to solve this problem. ${ }^{[14,15]}$ In the present article, the $\mathrm{Ni}$ single-crystal commercial grades CMSX-4 and René N4 are selected as the reference alloys, since their microstructural parameters and creep behavior during different creep tests have been reported in quite some detail. ${ }^{[1,16-19]}$ A novel computational design model predicting the microstructural development during the creep process is presented in which thermodynamic data are combined with an energy-based microstructural evolution model. The microstructural features are computationally linked to the chemical composition, and the simulated results are validated against experimental observations. Specifically, the conditions considered in this work correspond to the coalescence of cubic $\gamma^{\prime}$ precipitates at elevated service temperatures (above $1173 \mathrm{~K}, 900{ }^{\circ} \mathrm{C}$ ), leading to the lamellar structure under uniaxial $\langle 001\rangle$ tensile loading. Other loading conditions (uniaxial compression, multiaxial stress, cyclic loading, etc.) are outside the scope of this work.

\section{MODEL DESCRIPTION}

In this section, a model that combines thermodynamic calculations with two representative methods that describe the microstructural evolution of CMSX-4 and René N4 superalloys is presented. The effects of chemical compositions are introduced and the corresponding microstructural parameters can be predicted as a function of stress and temperature. For the relatively limited composition domain explored in this work, the composition dependence of dislocation behavior is ignored. The nominal chemical compositions of commercial superalloy CMSX-4 and René N4 are shown in Table I.

\section{A. Fedelich's Phenomenological Model}

Recently, Fedelich et al. ${ }^{[20]}$ measured the increase in the microstructural periodicity $\lambda$ and the $\gamma$ channel width $\omega$ of CMSX-4 commercial superalloys as a function of service time, temperature, and applied stress. An analytical expression was proposed, which seems to capture the findings from detailed observations on the transition of $\gamma^{\prime}$ morphology from cuboid to rafted shape. In their work, the processes of isotropic coarsening and unidirectional coarsening, i.e., rafting, are considered separately and are assumed to be governed by different driving mechanisms. Based on geometrical considerations, the channel width in the two different procedures is given by

$$
\begin{gathered}
\omega_{\text {cube }}(t)=\left(1-\sqrt[3]{f_{\gamma^{\prime}}}\right) \lambda(t) \\
\omega_{\text {raft }}(t)=\left(1-f_{\gamma^{\prime}}\right) \lambda(t),
\end{gathered}
$$

where $f_{\gamma^{\prime}}$ is the volume fraction of precipitates and $\lambda(t)$ is the microstructural periodicity. The isotropic coarsening of $\lambda(t)$ was captured by the fitted equation used for specimens crept at $1223 \mathrm{~K}\left(950{ }^{\circ} \mathrm{C}\right)$ :

$$
\lambda(t)=\lambda_{0} \sqrt{1+\beta t} .
$$

A dimensionless parameter, termed rafting degree $\xi$, is defined to quantify the microstructural changes. It presents the normalized channel width, which increases from 0 to 1 when the microstructure changes from cubes to plates:

$$
\xi=\frac{\omega(t)-\omega_{\text {cube }}(t)}{\omega_{\text {raft }}(t)-\omega_{\text {cube }}(t)} .
$$

The analytical expression to describe the degree of rafting as a function of time and external stress based on experimental results is given by

$$
\xi=1-\exp \left(-b \sigma^{n} t\right) .
$$

Fundamentally, the aforementioned model is an experimentally based analytical expression, which can be applied only for CMSX-4 alloy at the temperature $1223 \mathrm{~K}\left(950{ }^{\circ} \mathrm{C}\right)$, where $\beta, b$, and $n$ are all fitting parameters not having any physical meaning. To extend the application scope of this model over a wider temperature range, Fedelich et al. ${ }^{[21]}$ further collected the microstructural evolution data of CMSX-4 over a wide temperature range and built the following equation to describe the kinetics of evolving periodicity and channel width:

$$
\begin{aligned}
& \lambda_{[001]}=\lambda_{[001]}^{0}\left[1+D_{0} \exp \left(-\frac{Q_{\lambda}}{R T}\right) t\right]^{a} \\
\omega_{[001]}= & \omega_{\text {cube }}+\left(\omega_{\text {raft }}-\omega_{\text {cube }}\right) \\
& \times\left\{1-\exp \left[-A_{0} \exp \left(-\frac{Q_{\xi}}{R T}\right)\left(1+\frac{\sigma}{\sigma_{0}}\right)^{p} t\right]\right\} .
\end{aligned}
$$


Table I. Nominal Chemical Compositions of Commercial Superalloys CMSX-4 and René N4 (Weight Percent)

\begin{tabular}{lllllllll}
\hline & $\mathrm{Al}$ & $\mathrm{Co}$ & $\mathrm{Cr}$ & $\mathrm{W}$ & Mo & Ta & Ti & Re \\
\hline CMSX-4 & 5.6 & 9.0 & 6.5 & 6.0 & 0.6 & 6.5 & 1.0 \\
René N4 & 3.7 & 8.0 & 9.0 & 6.0 & 2.0 & 4.0 & 4.2 & -1.0 \\
\hline
\end{tabular}

In these two equations, $D_{0}, Q_{\lambda}, a, A_{0}, Q_{\xi}, \sigma_{0}$, and $p$ are also fitting parameters. This modified equation excellently describes the microstructural degradation of CMSX-4 at different stress and temperature levels with the correlation factors $r^{2}>0.97$. However, all the parameter values in the equation remain fitted values, which means for other superalloy systems with slightly different chemical compositions, the applicability of the model should be reassessed and the parameter values need to be redetermined.

\section{B. Fan's Model}

Fan et al. ${ }^{[22]}$ follow the approach of Fedelich et al.'s work $^{[20]}$ in describing the channel width and rafting degree but attempt to bring in a more physical approach. They describe the isotropic coarsening of the microstructural periodicity, as follows:

$$
\lambda(t)^{3}-\lambda_{0}^{3}=\frac{B Q}{R T} t .
$$

In this equation, $B$ is a material constant and $Q$ is the activation energy. One could argue that the Oswald ripening mechanism describes the coarsening of spherical particles, while the actual microstructure in the superalloys considered is a lamellar structure. However, it would be reasonable to simplify the coarsening kinetics of lamellar structures in the same way since, essentially, it is the overall interfacial energy that drives the coarsening mechanism. Recent studies ${ }^{[23,24]}$ also show that the isotropic coarsening rate, as in the LSW coarsening mechanism, can be applied as an indicator of creep properties in $\mathrm{Ni}$ superalloys. In this model, the isotropic coarsening rate is proportional to temperature and determined by two constants, while no formal connection to the chemical composition is assumed.

According to Fan's study, in the directional coarsening process, $\gamma^{\prime}$ precipitates only change their shape from cubes to rafts while the precipitate volume remains constant, since the change of $\gamma^{\prime}$ volume was included in the isotropic coarsening. The driving force for rafting is the strain energy $\psi$, which equals the distortion strain energy since the volumetric strain energy is zero. The strain energy during rafting is formulated as

$$
\psi=v_{\mathrm{d}}=(1-c \xi) \frac{1+v}{3 E} \sigma_{\mathrm{s}}^{2}
$$

where $v_{\mathrm{d}}$ is the distortion strain energy, $E$ is the elastic modulus, $v$ is the Poisson ratio, and $\sigma_{\mathrm{s}}$ is the largest Mises stress in three types of channels. From a thermodynamics perspective, the driving force for rafting is the partial derivative of the strain energy to the degree of rafting:

$$
F=-\frac{\partial \psi}{\partial \xi}=c \frac{1+v}{3 E} \sigma_{\mathrm{s}}^{2} .
$$

In the case of a uniaxial applied tensile stress in one of the three principal $\langle 001\rangle$ directions,

$$
\sigma_{s}=\left|\sigma_{0}+(1+\alpha) \sigma_{i}\right|
$$

This direction was selected since it leads to the highest von Mises stress value, which was taken to be the superimposition of extrinsic applied stress $\sigma_{0}$ and intrinsic lattice misfit stress $\sigma_{i}$, and $\sigma_{i}$ was set as a constant value $300 \mathrm{MPa}$ for CMSX-4 superalloy. Similarly, the evolution of the rafting degree $\xi$ is related to the actual morphology, the driving force, and the temperature. Hence, the channel width during rafting can be predicted with the following equation:

$$
\begin{aligned}
\omega(t)= & \omega_{\text {cube }}(t)+\left[\omega_{\text {raft }}(t)-\omega_{\text {cube }}(t)\right] \\
& \times\left\{1-\exp \left[-A \sigma_{\mathrm{s}}^{n} \exp \left(-\frac{Q}{R T}\right) t\right]\right\} .
\end{aligned}
$$

In this model, the microstructural parameter $\gamma$ channel width now is presented as a function of time, temperature, and stress. In contrast to Fedelich's work, every parameter in this equation has a clear physical meaning.

\section{Composition-Dependent Microstructural Model}

In this work, we also assume that the growth of microstructural periodicity follows the LSW theory but redefine the isotropic coarsening rate to present the proper effect of temperature. The isotropic coarsening rate of microstructural periodicity is shown in this equation:

$$
\lambda(t)^{3}-\lambda_{0}^{3}=K t
$$

where $t$ is the creep time. This equation resembles Eq. [8], but in contrast to the formulation of Eq. [8], our definition of $K$ allows for making a connecting to the equilibrium chemical composition of both the matrix and the precipitate as well as the diffusivities of the alloying elements. Based on earlier work, ${ }^{[25-28]}$ the rate constant for the isotropic coarsening rate of precipitates is given by the following equation:

$$
K=8 \gamma V_{m}^{p} / \sum_{i=1}^{n} \frac{9\left(x_{i}^{p}-x_{i}^{m p}\right)^{2}}{x_{i}^{m p} D_{i} / \mathrm{R} T}
$$

in which $V_{m}^{p}$ is the molar volume of precipitate, $x$ is the equilibrium interface mole fraction of the $\gamma^{\prime}$ forming elements on both the matrix $(m)$ and precipitate $(p)$ sides, $T$ is the service temperature, and $D$ is the corresponding diffusion coefficient. In the calculations, the interfacial energy is arbitrarily set at a fixed value of 
$0.3 \mathrm{~J} / \mathrm{m}^{2}$ irrespective of the precipitate size and the actual composition of precipitate and matrix. ${ }^{[29]}$ This is a slight simplification but helps in illustrating the effect of alloy and particle composition on precipitate coarsening. All thermodynamic parameter values, including $x_{i}^{p}, x_{i}^{m p}, D_{i}$, and $V_{m}^{p}$, required during the calculations were calculated via Thermo-Calc using the latest TCNI8 and MobNI4 databases.

In addition to the coarsening rate, the misfit stress induced by the mismatch of lattice parameter and elasticity coefficient is also treated as a composition-dependent parameter. In this work, the lattice misfit stress is defined as $\sigma_{i}$ which is taken as the product of the Young's modulus and the lattice misfit strain, as shown in Eq. [15]

$$
\begin{gathered}
\sigma_{\delta}=|E \delta| \\
\delta=\frac{2\left(a_{\gamma^{\prime}}-a_{\gamma}\right)}{a_{\gamma^{\prime}}+a_{\gamma}} .
\end{gathered}
$$

The lattice misfit stress is determined by the element concentration in $\gamma / \gamma^{\prime}$ phases as well as the thermal expansion coefficients of both phases. In fact, apart from the internal stress induced by lattice misfit, the elastic misfit between the $\gamma / \gamma^{\prime}$ phase contributes to internal stress as well. Dye et al.'s research ${ }^{[30]}$ revealed that at temperatures above $1173 \mathrm{~K}\left(900{ }^{\circ} \mathrm{C}\right)$, the differences in the elastic moduli between $\gamma / \gamma^{\prime}$ phases in a CMSX-4 superalloy are within 5 pct. Therefore, in our work, the internal stress is simplified as the lattice misfit stress only.

The evolution of channel width in CMSX-4 superalloy during rafting is presented in the following equation:

$$
\begin{aligned}
\omega(t)= & \omega_{\text {cube }}(t)+\left[\omega_{\text {raft }}(t)-\omega_{\text {cube }}(t)\right] \\
& \times\left\{1-\exp \left[-A \sigma_{s}^{n} \exp \left(-\frac{Q}{R T}\right) t\right]\right\} .
\end{aligned}
$$

As mentioned previously, the lattice misfit between the $\gamma / \gamma^{\prime}$ phase is, on the one hand, governed by the chemical composition of the phases at the relevant temperature via Vegard's law and, on the other hand, by the thermal expansion coefficients of both phases. In this article, the calculation of lattice misfit follows the method from Rettig et al. ${ }^{[14]}$ The misfit is determined by Eqs. [18] through [21], which concern element concentrations of the respective phases at the required temperature.

$$
\begin{aligned}
a_{\gamma}^{R T}= & 3.524+0.0196 x_{\mathrm{Co}}^{\gamma}+0.110 x_{\mathrm{Cr}}^{\gamma}+0.478 x_{\mathrm{Mo}}^{\gamma} \\
& +0.444 x_{\mathrm{W}}^{\gamma}+0.441 x_{\mathrm{Re}}^{\gamma}+0.3125 x_{\mathrm{Ru}}^{\gamma}+0.179 x_{\mathrm{Al}}^{\gamma} \\
& +0.422 x_{\mathrm{Ti}}^{\gamma}+0.7 x_{\mathrm{Ta}}^{\gamma}
\end{aligned}
$$

$$
\begin{aligned}
a_{\gamma^{\prime}}^{R T}= & 3.57-0.004 x_{\mathrm{Cr}}^{\gamma^{\prime}}+0.208 x_{\mathrm{Mo}}^{\gamma^{\prime}}+0.194 x_{\mathrm{W}}^{\gamma^{\prime}} \\
& +0.262 x_{\mathrm{Re}}^{\gamma^{\prime}}+0.1335 x_{\mathrm{Ru}}^{\gamma^{\prime}}+0.258 x_{\mathrm{Ti}}^{\gamma^{\prime}}+0.5 x_{\mathrm{Ta}}^{\gamma^{\prime}}
\end{aligned}
$$

Fig. 1-Comparison of the calculated channel width of CMSX-4 superalloy with the experimental data from Fedelich and Eggeler at the temperature of $1123 \mathrm{~K}\left(850{ }^{\circ} \mathrm{C}\right)(\mathrm{a}), 1223 \mathrm{~K}\left(950{ }^{\circ} \mathrm{C}\right)(\mathrm{b}), 1323 \mathrm{~K}$ $\left(1050{ }^{\circ} \mathrm{C}\right)(\mathrm{c})$, and $1373 \mathrm{~K}\left(1100^{\circ} \mathrm{C}\right)(\mathrm{d})$; and the comparison of René N4 microstructural parameters at $1144 \mathrm{~K}\left(871{ }^{\circ} \mathrm{C}\right)$ and $1255 \mathrm{~K}$ $\left(982{ }^{\circ} \mathrm{C}\right)(\mathrm{e})($ Color figure online).

and

$$
\begin{gathered}
a_{\gamma}=a_{\gamma}^{R T}+5.741 \times 10^{-5} T-1.01 \times 10^{-9} T^{2} \\
a_{\gamma^{\prime}}=a_{\gamma^{\prime}}^{R T}+6.162 \times 10^{-5} T-1.132 \times 10^{-8} T^{2} .
\end{gathered}
$$

The element concentrations of $\gamma / \gamma^{\prime}$ phases can be directly obtained from CALPHAD calculation and the simulated lattice misfit. In the absence of better data and reliable ab-initio calculations, the empirical Eqs. [18] through [21] are used to calculate the lattice misfits.

Since the predictions of this model rely on the accuracy of the underlying database (as all thermodynamic calculations), we checked the validity of the database used in predicting the characteristics of $\mathrm{Ni}$ superalloys. Disagreements between experimental results and simulated volume fractions and chemical compositions of $\gamma / \gamma^{\prime}$ phases have been reported when use was made of the formal TCNI databases, ${ }^{[31,32]}$ but recent publications have validated the reliability of the current databases TCNI8. ${ }^{[33,34]}$ Modest deviations between the actual experimental data topologically-closed-packed (TCP) phases and the recalculated values on the basis of the database are reported in Reference 35 . Hence, the results of the thermodynamic calculations for TCP phases should be considered as indicative.

\section{RESULTS}

Figure 1 shows the simulated channel width of commercial alloys CMSX-4 and René N4 obtained from our model and the comparison with the experimental data at different temperatures and applied stress levels. The solid lines are the simulation results obtained from our model, while the dashed lines are the results from Fedelich's analytical expression (Eq. [7]). It turns out in Figure 1 (a) that at $1123 \mathrm{~K}\left(850{ }^{\circ} \mathrm{C}\right)$, at the lowest stress level, a misfit exists between our predictions and the experimental data. However, at high stress levels, our model perfectly reproduces the experimental results and even outperforms Fedelich's analytical expression. Figure 1(b) shows that at a service temperature of $1223 \mathrm{~K}\left(950{ }^{\circ} \mathrm{C}\right)$, a good agreement in the kinetics is obtained for the high stress $240 \mathrm{MPa}$, while at lower stresses, the kinetics of the channel widening process are slightly overestimated. From Figure 1(c), it can be deduced that our model predictions fit quite well with Eggeler's experimental data obtained at $1323 \mathrm{~K}$ $\left(1050{ }^{\circ} \mathrm{C}\right) .{ }^{[36]}$ The results in Figure $1(\mathrm{~d})$ show that at $1373 \mathrm{~K}\left(1100{ }^{\circ} \mathrm{C}\right)$, the channel characteristics are also slightly overestimated by our simulation, but the 


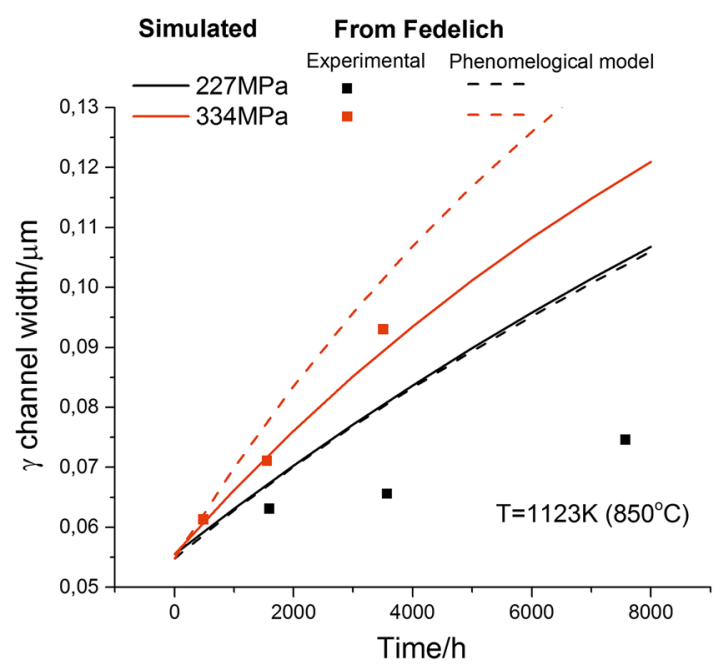

(a)

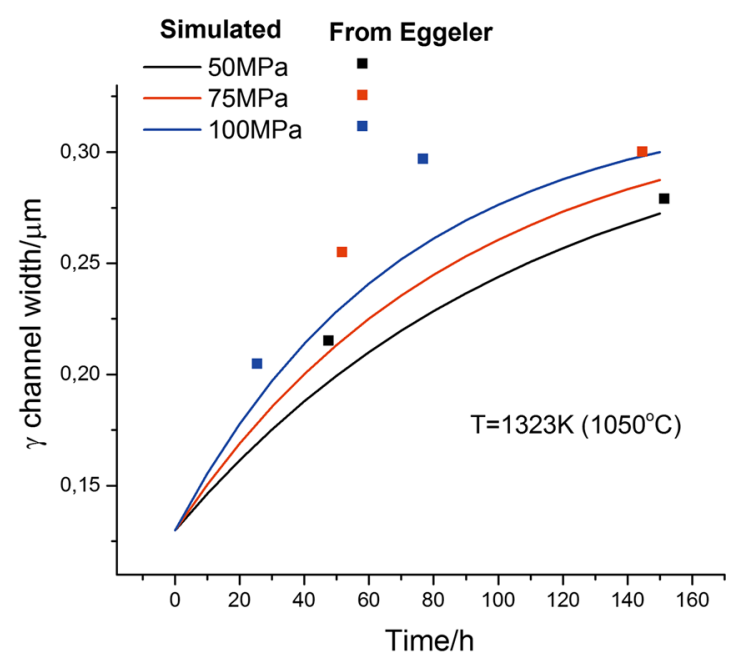

(c)

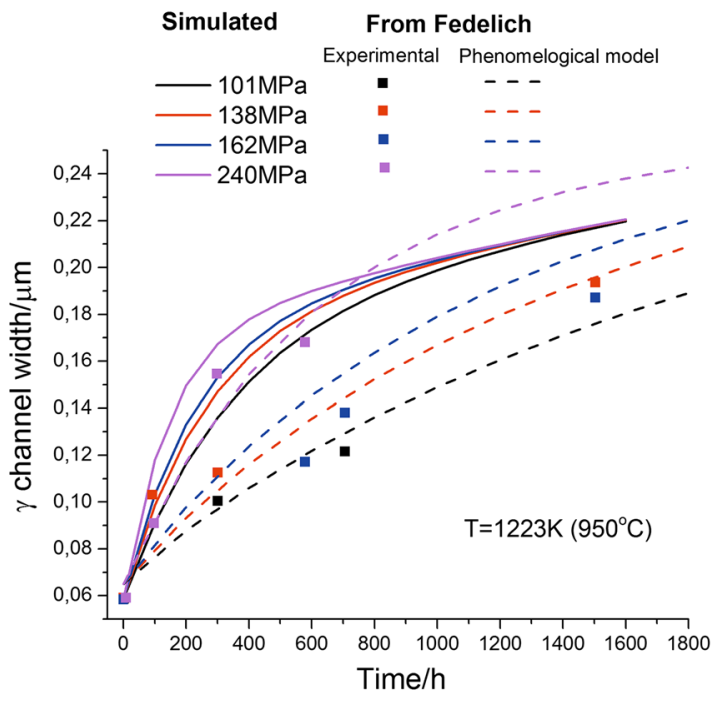

(b)

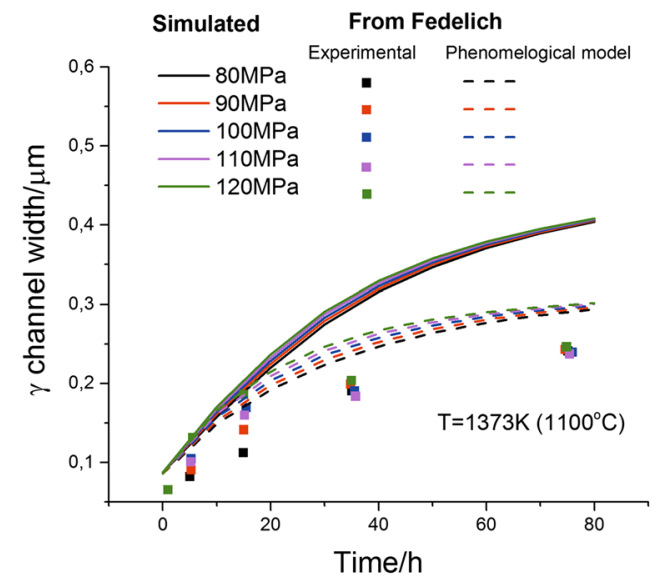

(d)

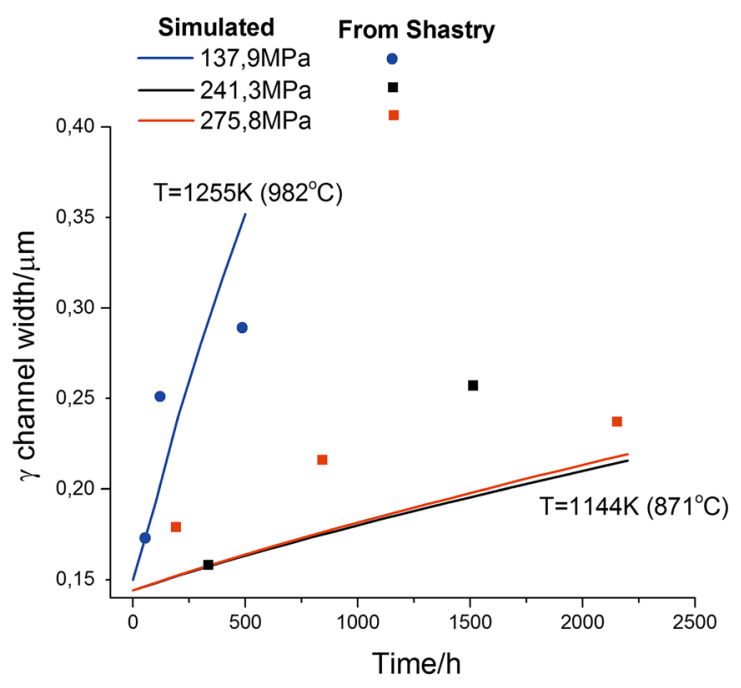

(e) 
tendency of convergence is well predicted. To validate our model for other compositions than that of CMSX-4, the evolution of $\gamma$ channel width in $\mathrm{Ni}$ commercial grades René N4, as reported by Shastry et al., ${ }^{[19]}$ was employed, and the comparison with simulation results is shown in Figure 1(e). At a temperature of $1144 \mathrm{~K}$ $\left(871^{\circ} \mathrm{C}\right)$, the predictions are rather lower than the experimental observation, while at a higher temperature of $1255 \mathrm{~K}\left(982^{\circ} \mathrm{C}\right)$, the prediction suits the experimental results perfectly. It is necessary to point out that for our model, which has no fitting parameter in the calculation at all and only uses independently derived physical parameter values, the agreement of the predictions at diverse levels of temperature, stress, and different compositions is remarkable. As such, it is one of the first models that manages to couple the microstructural characteristics of the rafting process with the chemical composition-based thermodynamic calculation in $\mathrm{Ni}$ superalloys.

\section{A. Effect of Alloying Element on Microstructure and Creep Properties}

For Ni superalloys, the microstructural features and their evolution during creep are intrinsically determined by the type and concentration of the various alloying elements. For example, Al and Ta are the main $\gamma^{\prime}$ forming elements and higher levels of these elements can effectively increase the $\gamma^{\prime}$ volume fraction. ${ }^{[37]}$ Mo and Co partition preferentially in $\gamma$ matrix and play as strong solid-solution-strengthening elements to elevate the creep properties, ${ }^{[38-40]}$ while Co addition helps to reduce the tendency to form TCP phases. ${ }^{[41,42]} \mathrm{Cr}$ was found to increase the $\gamma^{\prime}$ volume fraction ${ }^{[38]}$ but deteriorates the microstructural stability at high level of concentration. ${ }^{[43]}$ Re addition can substantially lower the $\gamma^{\prime}$ coarsening kinetics and helps to bring about large negative misfits, but also increases the tendency to form Rerich TCP phases. ${ }^{[4,45]} \mathrm{Ru}$ can effectively stabilize the microstructure by suppressing the precipitation of TCP phases. ${ }^{[34,46]}$

We now attempt to predict the effect of the concentration of specific alloying elements on the microstructure and rafting kinetics, taking the base composition of CMSX-4 superalloy as the starting point. The change in alloy composition is obtained at the expense of varying $\mathrm{Ni}$ concentration. The service temperature, total time, and applied stress are set as $1273 \mathrm{~K}\left(1000^{\circ} \mathrm{C}\right)$, 200 hours, and $100 \mathrm{MPa}$, respectively, and the predicted trends are compared with the experimental observations reported in the literature. All alloying concentrations are given in weight percent.

\section{Cr effect}

The predicted effects of $\mathrm{Cr}$ on the microstructural parameters and $\gamma^{\prime}$ coarsening rate are shown in Figure 2. The calculation results show that as the $\mathrm{Cr}$ concentration increases, the value of $\gamma$ channel width varies but the changes are minor. The $\gamma^{\prime}$ coarsening rate decreases slightly when the $\mathrm{Cr}$ levels increase from 2 to 10 pct, and the decrease becomes sharper as $\mathrm{Cr}$ increases from 10 to 14 pct. The $\gamma^{\prime}$ volume fraction decreases slowly but continuously with the $\mathrm{Cr}$ level. When the $\mathrm{Cr}$ level reaches $11 \mathrm{pct}$, the TCP phases, including the $\mu$ and $\sigma$ phases, are predicted to start to precipitate.

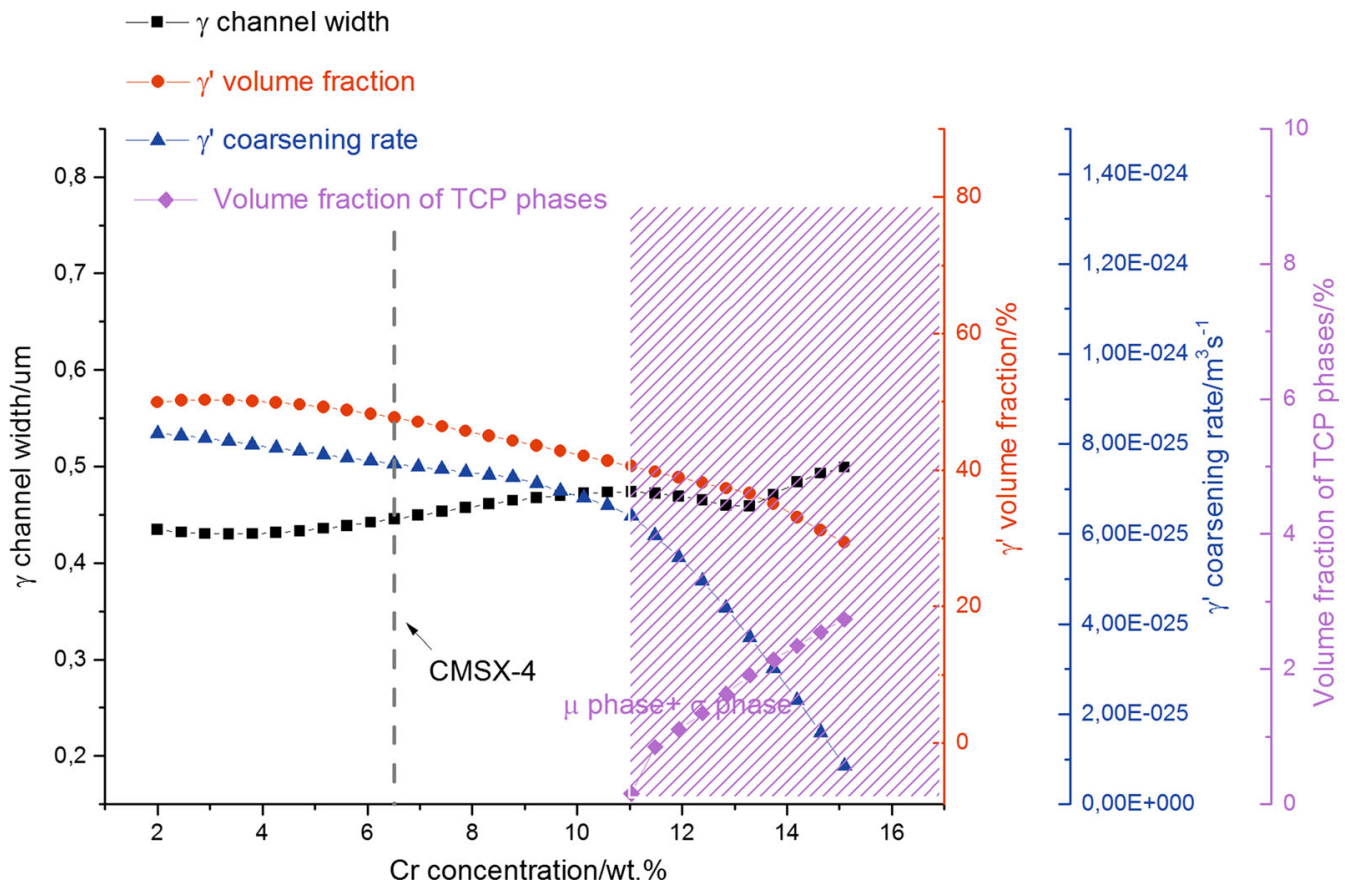

Fig. 2-Effect of $\mathrm{Cr}$ on the $\gamma$ channel width, $\gamma^{\prime}$ volume fraction, and $\gamma^{\prime}$ coarsening rate. The dashed region marks the formation of undesirable phases (Color figure online). 
The predicted influence of the $\mathrm{Cr}$ level on the volume fraction is in good agreement with the experimental observations by Mackay et al. ${ }^{[40]}$ and Huo et al., ${ }^{[13]}$ which showed that $\mathrm{Cr}$ helps to develop the $\gamma^{\prime}$ volume fraction in Ni superalloy. Huo et al.'s data also indicate that a $\mathrm{Cr}$ addition contributes to narrowing the $\gamma$ channel width, which also agrees well with the predictions. Carroll et al.'s ${ }^{[37]}$ and Chen et al.'s ${ }^{[47]}$ investigations show that an increasing $\mathrm{Cr}$ level helps to improve the creep strength of Ni superalloys. This result can be explained by the effect of $\mathrm{Cr}$ on decreasing $\gamma^{\prime}$ coarsening rate, as shown in this figure. Besides, it also has been reported $^{[12,13]}$ that high $\mathrm{Cr}$ levels can deteriorate the microstructural stability by increasing the proneness to TCP phase formation, in accordance with the simulation results reflected by the pink dots. In this figure, the backward slash patterns define areas where undesirable phases precipitate. From the simulations presented in Figure 2 and assuming the thermodynamic database to be sufficiently validated and correct (refer to the validity comment at the end of the model introduction section), it can be concluded that the $\mathrm{Cr}$ level can be increased in the base CMSX-4 alloy, to further retard the coarsening rate without the occurrence of TCP phase formation.

\section{Co effect}

As shown in Figure 3, a rise in Co level from 0 to $16 \mathrm{wt}$ pct brings a continuous increase in $\gamma$ channel width and a continuous drop in $\gamma^{\prime}$ volume fraction from 71 to 48 pct, while the $\gamma^{\prime}$ coarsening rate decreases simultaneously. Over the entire Co concentration range, no signs of the existence of TCP phases are found, which agrees well with the experimental investigations ${ }^{[43]}$ showing that Co addition helps to suppress the formation of TCP phases.
The predicted effect of Co on decreasing the $\gamma^{\prime}$ volume fraction fits well with MacKay's investigation. ${ }^{[40,48]}$ In contrast, Huo et al.' ${ }^{[13]}$ experimental results show that an $8 \mathrm{wt}$ pct addition of $\mathrm{Co}$ can slightly reduce the $\gamma^{\prime}$ volume fraction to 3 pct. This mismatch reflects the complex effect of Co on $\gamma^{\prime}$ precipitation, which can be ascribed to the effect of Co on altering the $\gamma / \gamma^{\prime}$ partitioning behavior of other alloying elements. ${ }^{[49]}$

\section{Ta effect}

The effect of Ta on the microstructural parameters of $\gamma / \gamma^{\prime}$ phases is shown in Figure 4. The calculated results show that if the $\mathrm{Ta}$ concentration increases from 4 to $12 \mathrm{pct}$, the value of $\gamma$ channel width is almost halved, while the $\gamma^{\prime}$ volume fraction increases continuously from 39 to 60 pct and the $\gamma^{\prime}$ coarsening rate has a sustained decrease. The simulated results agree well with Jena's experimental investigations, showing that Ta promotes $\gamma^{\prime}$ formation as a $\gamma^{\prime}$ former, ${ }^{[50]}$ and Forde's study showing that Ta addition helps to retard diffusion-mediated processes in Ni-based systems. ${ }^{[51]}$ When the Ta content reaches 8.1 pct, Cr-enriched $\sigma$ phase begins to precipitate, as shown by pink dots and the area marked by the slash pattern. It has been demonstrated by Karunaratne et al.'s experimental results that the Ta addition increases the susceptibility to TCP formation by concentrating the $\gamma$-partitioning TCP-forming elements in the $\gamma$ phase ${ }^{[52]}$; Specifically, Booth-Morrison et al.'s study shows that Ta increases the partitioning ratio for $\mathrm{Cr}$ by displacing $\mathrm{Cr}$ atoms from the $\gamma^{\prime}$ phase, ${ }^{[53]}$ in this way promoting TCP formation. The reported experimental observations are well predicted by the model presented here.

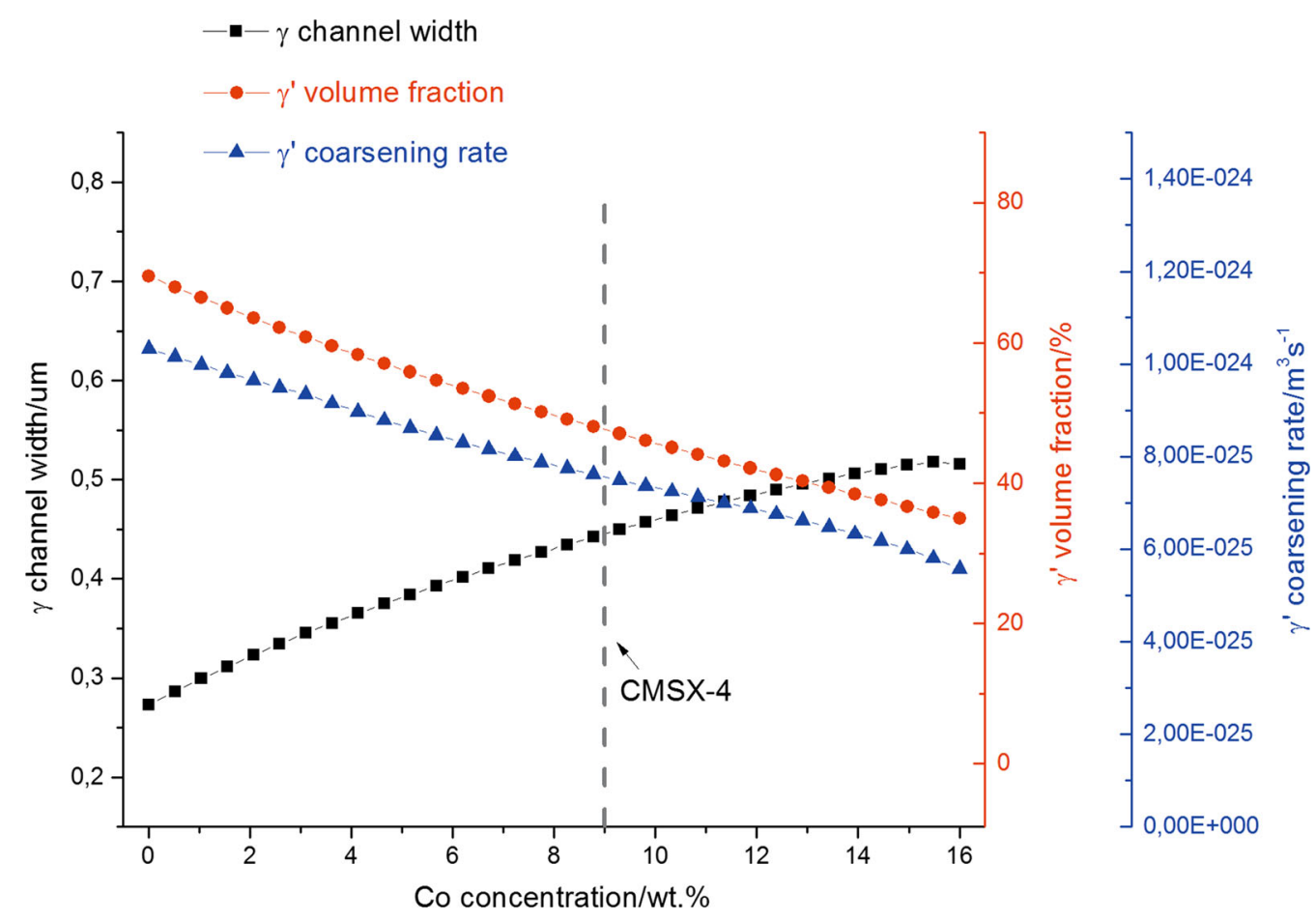

Fig. 3-Effect of Co on the $\gamma$ channel width, $\gamma^{\prime}$ volume fraction, and $\gamma^{\prime}$ coarsening rate (Color figure online). 


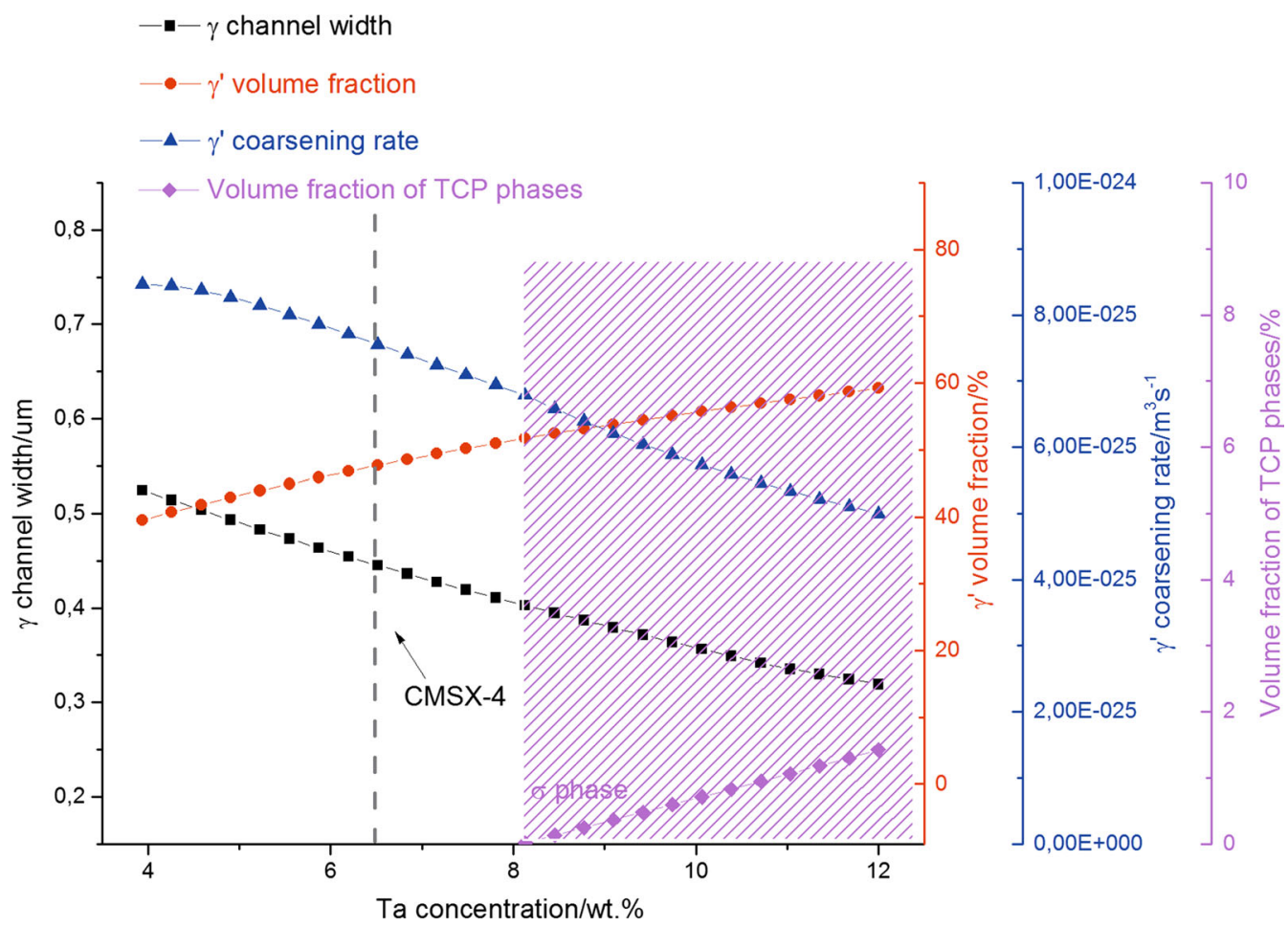

Fig. 4-Effect of Ta on the $\gamma$ channel width, $\gamma^{\prime}$ volume fraction, and $\gamma^{\prime}$ coarsening rate. The dashed region marks the formation of undesirable phases (Color figure online).

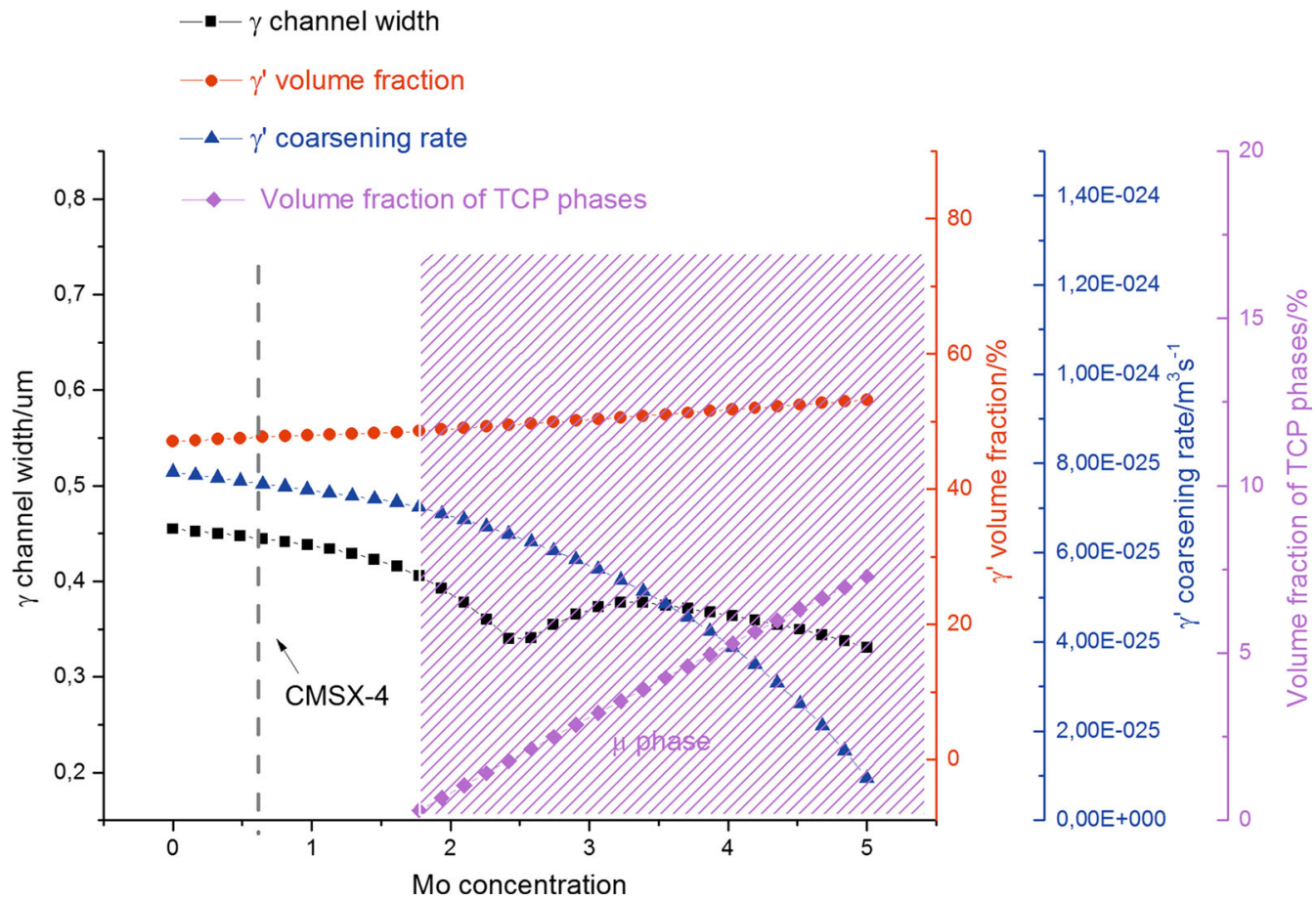

Fig. 5-Effect of Mo on the $\gamma$ channel width, $\gamma^{\prime}$ volume fraction, and $\gamma^{\prime}$ coarsening rate. The dashed region marks the formation of undesirable phases (Color figure online).

4. Mo effect

Figure 5 shows that the $\gamma$ channel width drops from 0.45 to $0.3 \mu \mathrm{m}$ as the Mo concentration increases from 0 to $2.5 \mathrm{wt}$ pct. After that, the channel width experiences a slow increase and then keeps decreasing with a further increase in Mo concentration. Besides, the figure shows 


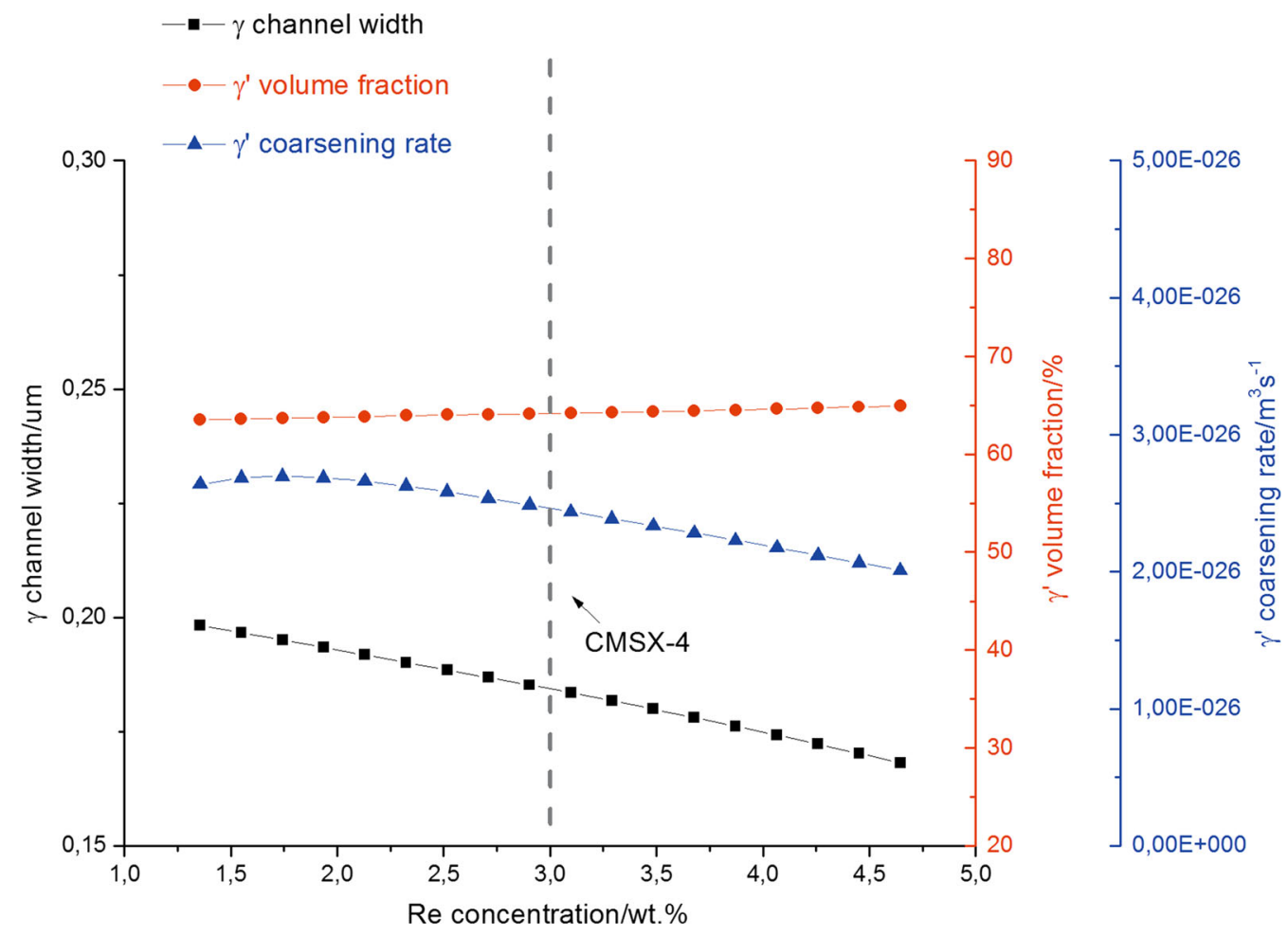

Fig. 6-Effect of Re on the $\gamma$ channel width, $\gamma^{\prime}$ volume fraction, and $\gamma^{\prime}$ coarsening rate (Color figure online).

that Mo additions can slightly increase the volume fraction of $\gamma^{\prime}$ precipitates and reduce the $\gamma^{\prime}$ coarsening rate by a factor 8 when the Mo concentration rises from 0 to 5 pct. However, the undesirable $\mu$ phase begins to precipitate and grow rapidly for Mo concentrations in excess of 1.7 pct. The simulation results for the $\gamma$ channel width and $\gamma^{\prime}$ volume fraction fit well with Huo et al.'s data, ${ }^{[13]}$ which showed that 1.5 pet addition of Mo can slightly increase the precipitation volume fraction and decrease the $\gamma$ channel width. Moreover, Biss and Sponseller's experimental results ${ }^{[54]}$ showing that Mo addition can retard the coarsening rate of $\gamma^{\prime}$ particles also agree well with the calculated results. The role of Mo as a strong TCP former has been investigated experimentally by many researchers, ${ }^{[11,12]}$ and their results confirm the simulation results that an elevated level of Mo promotes the formation of the detrimental $\mu$ phase. The forbidden area with the presence of $\mu$ phase is marked by a backward slash pattern. It is also worth mentioning here that the model predictions suggest that there still exists some space to increase the Mo concentration in the base CMSX-4 alloy, as it leads to a higher precipitation volume fraction and a lower coarsening rate while the TCP phases should remain absent.

\section{Re effect}

Finally, Figure 6 shows that according to the simulations based on the existing data in the TCNI8 and MobNI4 thermodynamic databases, Re additions can slightly decrease the $\gamma$ channel width, while the $\gamma^{\prime}$ volume fraction remains more or less unchanged. The blue dots indicate that the coarsening rate of $\gamma^{\prime}$ precipitates experiences a slow decrease when the Re level increases from 1 to 5 pct. Besides, TCP phases are predicted not to form over the entire concentration range of Re from 1 to 5 pct. According to the experimental results by Heckl et al., ${ }^{[44]}$ a 2 at. pet $\mathrm{Re}$ addition can significantly reduce the $\gamma^{\prime}$ volume fraction to 15 pct. Besides, the effect of Re on the coarsening rate of $\gamma^{\prime}$ has also been investigated extensively. The conclusions are quite consistent and indicate that $\mathrm{Re}$ addition in $\mathrm{Ni}$ superalloys can effectively retard the $\gamma^{\prime}$ coarsening rates, ${ }^{[55,56]}$ due to the fact that $\mathrm{Re}$ is the slowest diffusing element in $\mathrm{Ni}$ among all alloy elements. ${ }^{[57,58]}$ The calculated results are in qualitative agreement with the reported effect of Re, but the high efficiency of $\mathrm{Re}$ in lowering the coarsening rate as well as decreasing the $\gamma^{\prime}$ volume fraction is quantitatively not captured very well. It might be that the data in the thermodynamic databases TCNI8 and MobNI4 regarding the impact of the element $\mathrm{Re}$ need some adjustment.

To sum, our model can semiquantitatively predict the effect of chemical composition of Ni-based superalloys on $\gamma$ channel width at a relatively high temperature and low stress range on the basis of hard physical data rather than empirical fitted parameter values, which reflects the power of the model in simulating the microstructural evolutions during the rafting process. The effect of alloying elements $\mathrm{Cr}, \mathrm{Co}, \mathrm{Ta}, \mathrm{Mo}$, and $\mathrm{Re}$ in CMSX-4 superalloy on the microstructural parameters, $\gamma^{\prime}$ coarsening rates, and microstructural stability are calculated by this model, and the simulated results have qualitatively good agreement with the experimental results from the literature. Moreover, our calculation 
shows that the chemical composition of CMSX-4 superalloy has not reached the optimal values from a thermomechanical stability perspective. There still exists some space to increase the alloying levels of $\mathrm{Cr}$, $\mathrm{Ta}$, and Mo to further improve the precipitation strengthening while maintaining the microstructural stability of the matrix.

\section{CONCLUSIONS}

1. A novel computational model for the microstructural stability of Ni-based single-crystal superalloys as a function of temperature and applied tensile stress was built by combining thermodynamics calculations and an energy-based microstructural model. The connection between chemical compositions and the rate of microstructural evolution is based on the isotropic coarsening of $\gamma^{\prime}$ phase and $\gamma /$ $\gamma^{\prime}$ lattice misfit during creep.

2. The model was applied to predict the $\gamma$ channel widening of $\mathrm{Ni}$ commercial grades of CMSX-4. The microstructural characteristics of the rafting process, especially at elevated temperature, can be well simulated by the model.

3. The effect of alloying elements $\mathrm{Cr}, \mathrm{Co}, \mathrm{Mo}$, and $\mathrm{Re}$ on the microstructural parameters, $\gamma^{\prime}$ coarsening rates, and microstructural stability in CMSX-4 superalloy were analyzed by this model. The simulated results are well confirmed by the reported experimental data. The calculated results show that from a thermomechanical stability point of view, the chemical composition of the CMSX-4 superalloy has not reached its optimal value. There still exists some space to increase the alloying level of $\mathrm{Cr}$, $\mathrm{Ta}$, and $\mathrm{Mo}$, to further improve the precipitation strengthening while maintaining the microstructural stability of the matrix.

\section{ACKNOWLEDGMENTS}

This work was carried out with financial support from the Chinese Scholarship Council (CSC) as well as TU Delft internal funding. The authors thank Dr. Bernard Fedelich, Federal Institute for Materials Research and Testing (BAM), for helpful discussions during the early stages of the preparation of the manuscript.

\section{OPEN ACCESS}

This article is distributed under the terms of the Creative Commons Attribution 4.0 International License (http://creativecommons.org/licenses/by/4.0/), which permits unrestricted use, distribution, and reproduction in any medium, provided you give appropriate credit to the original author(s) and the source, provide a link to the Creative Commons license, and indicate if changes were made.

\section{REFERENCES}

1. R.C. Reed: The Superalloys: Fundamentals and Applications, Cambridge University Press, Cambridge, United Kingdom, 2008.

2. Z. Zhu, H. Basoalto, N. Warnken, and R.C. Reed: Acta Mater., 2012, vol. 60 , pp. $4888-4900$

3. S. Gao, M. Fivel, A. Ma, and A. Hartmaier: J. Mech. Phys. Solids, 2017, vol. 102, pp. 209-23.

4. V.A. Vorontsov, R.E. Voskoboinikov, and C.M.F. Rae: Advanced Materials Research, Trans Tech Publications, Aedermannsdorf, 2011, pp. 150-55.

5. M. Cottura, B. Appolaire, A. Finel, and Y. Le Bouar: J. Mech. Phys. Solids, 2016, vol. 94, pp. 473-89.

6. Y.S. Choi, T.A. Parthasarathy, C. Woodward, D.M. Dimiduk, and M.D. Uchic: Metall. Mater. Trans. A, 2012, vol. 43A, pp. 1861-69.

7. F.R.N. Nabarro, C.M. Cress, and P. Kotschy: Acta Mater., 1996, vol. 44, pp. 3189-98.

8. T. Ohashi, K. Hidaka, and S. Imano: Acta Mater., 1997, vol. 45, pp. 1801-10

9. J.C. Chang and S.M. Allen: J. Mater. Res., 1991, vol. 6, pp. $1843-55$

10. W.-P. Wu, Y.-F. Guo, G.-S. Dui, and Y.-S. Wang: Comput. Mater. Sci., 2008, vol. 44, pp. 259-64.

11. X.G. Liu, L. Wang, L.H. Lou, and J. Zhang: J. Mater. Sci. Technol., 2015, vol. 31, pp. 143-47.

12. B. Wang, J. Zhang, T. Huang, S. Haijun, Z. Li, L. Liu, and F. Hengzhi: J. Mater. Res., 2016, vol. 31, pp. 3381-89.

13. J.J. Huo, Q.Y. Shi, and Q. Feng: Mater. Sci. Eng. A, 2017, vol. 693, pp. 136-44.

14. R. Rettig, N.C. Ritter, H.E. Helmer, S. Neumeier, and R.F. Singer: Model. Simul. Mater. Sci., 2015, vol. 23, p. 035004.

15. R.C. Reed, T. Tao, and N. Warnken: Acta Mater., 2009, vol. 57, pp. $5898-5913$.

16. A. Epishin, T. Link, H. Klingelhöffer, B. Fedelich, U. Brückner, and P.D. Portella: Mater. Sci. Eng. A, 2009, vol. 510, pp. 262-65.

17. A. Scholz, Y. Wang, S. Linn, C. Berger, and R. Znajda: Mater. Sci. Eng. A, 2009, vol. 510, pp. 278-83.

18. A. Epishin, T. Link, M. Nazmy, M. Staubli, H. Klingelhoffer, and G. Nolze: Superalloys, 2008, pp. 725-31.

19. C. Girish Shastry, V. Sivakumar, G. Kelekanjeri, T. Vishwanath, and S. Chaudhuri: Mater. Sci. Eng. A, 2013, vol. 585, pp. 47-56.

20. B. Fedelich, G. Künecke, A. Epishin, T. Link, and P. Portella: Mater. Sci. Eng. A, 2009, vols. 510-511, pp. 273-77.

21. B. Fedelich, A. Epishin, T. Link, H. Klingelhöffer, G. Künecke, and P.D. Portella: Superalloys 2012, TMS, Warrendale, PA, 2012, pp. 491-500.

22. Y.-N. Fan, H.-J. Shi, and W.-H. Qiu: Mater. Sci. Eng. A, 2015, vol. 644, pp. 225-33.

23. J. Gong, D. Snyder, T. Kozmel, C. Kern, J.E. Saal, I. Berglund, J. Sebastian, and G. Olson: $J O M, 2017$, vol. 69, pp. 880-85.

24. C. Ai, X. Zhao, J. Zhou, H. Zhang, L. Liu, Y. Pei, S. Li, and S. Gong: J. Alloys Compd., 2015, vol. 632, pp. 558-62.

25. Q. Lu, W. Xu, and S. van der Zwaag: Philos. Mag., 2013, vol. 93, pp. 3391-3412.

26. Q. Lu, W. Xu, and S. van der Zwaag: Comput. Mater. Sci., 2014, vol. 84, pp. 198-205.

27. Q. Lu, W. Xu, and S. van der Zwaag: Acta Mater., 2014, vol. 77, pp. 310-23.

28. Q. Lu, W. Xu, and S. van der Zwaag: Acta Mater., 2014, vol. 64, pp. 133-43.

29. X. Yang, W. Hu, and X. Zhang: Appl. Surf. Sci., 2013, vol. 264, pp. 563-69.

30. D. Dye, J. Coakley, V.A. Vorontsov, H.J. Stone, and R.B. Rogge: Scr. Mater., 2009, vol. 61, pp. 109-12.

31. Y. Amouyal, Z. Mao, and D.N. Seidman: Acta Mater., 2010, vol. 58 , pp. $5898-5911$

32. M. Palumbo, D. Baldissin, L. Battezzati, O. Tassa, R. Wunderlich, H.J. Fecht, R. Brooks, and K. Mills: Materials Science Forum, Trans Tech Publications, Aedermannsdorf, 2006, pp. 591-96. 
33. S.C.H. Llewelyn, K.A. Christofidou, V.J. Araullo-Peters, N.G. Jones, M.C. Hardy, E.A. Marquis, and H.J. Stone: Acta Mater., 2017, vol. 131, pp. 296-304.

34. K. Matuszewski, A. Müller, N. Ritter, R. Rettig, K.J. Kurzydłowski, and R.F. Singer: Adv. Eng. Mater., 2015, vol. 17, pp. 1127-33.

35. K. Matuszewski, R. Rettig, H. Matysiak, Z. Peng, I. Povstugar, P. Choi, J. Müller, D. Raabe, E. Spiecker, K.J. Kurzydłowski, and R.F. Singer: Acta Mater., 2015, vol. 95, pp. 274-83.

36. K. Serin, G. Göbenli, and G. Eggeler: Mater. Sci. Eng. A, 2004, vol. 387, pp. 133-37.

37. L.J. Carroll, Q. Feng, and T.M. Pollock: Metall. Mater. Trans. A, 2008, vol. 39A, pp. 1290-1307.

38. R.A. MacKay, T.P. Gabb, A. Garg, R.B. Rogers, and M.V. Nathal: NASA Glenn Research Center, Cleveland, OH, unpublished research, 2012.

39. J.X. Zhang, T. Murakumo, H. Harada, and Y. Koizumi: Scr. Mater., 2003, vol. 48, pp. 287-93.

40. R.A. MacKay, T.P. Gabb, A. Garg, R.B. Rogers, and M.V. Nathal: Mater. Charact., 2012, vol. 70, pp. 83-100.

41. G.L. Erickson: Superalloys 1996, TMS, Warrendale, PA, 1996, pp. $35-44$.

42. W.S. Walston, K.S. O'Hara, E.W. Ross, T.M. Pollock, and W.H Murphy: Superalloys 1996, TMS, Warrendale, PA, 1996, pp. 27-34.

43. C.M.F. Rae and C. Roger: Reed. Acta Mater., 2001, vol. 49, pp. 4113-25.

44. A. Heckl, S. Neumeier, M. Göken, and R.F. Singer: Mater. Sci. Eng. A, 2011, vol. 528, pp. 3435-44.
45. P. Caron and T. Khan: Aerosp. Sci. Technol., 1999, vol. 3, pp. 513-23.

46. K. Matuszewski, R. Rettig, and R.F. Singer: MATEC Web Conference, EDP Sciences, 2014, p. 09001.

47. J.Y. Chen, Q. Feng, L.M. Cao, and Z.Q. Sun: Mater. Sci. Eng. A, 2011, vol. 528, pp. 3791-98.

48. M.V. Nathal and L.J. Ebert: Metall. Trans. A, 1985, vol. 16A, pp. 1849-62.

49. R.L. Dreshfield and K.J. Thomas: unpublished research, 2005 .

50. A.K. Jena and M.C. Chaturvedi: J. Mater. Sci., 1984, vol. 19, pp. 3121-39.

51. P.T. Forde: Adv. Mater. Process., 1996, vol. 149, p. 4.

52. M.S.A. Karunaratne, C.M.F. Rae, and R.C. Reed: Metall Mater. Trans. A, 2001, vol. 32A, pp. 2409-21.

53. C. Booth-Morrison, Z. Mao, R.D. Noebe, and D.N. Seidman: Appl. Phys. Lett., 2008, vol. 93, p. 033103.

54. V. Biss and D.L. Sponseller: Metall. Trans., 1973, vol. 4, pp. 1953-60.

55. A.F. Giamei and D.L. Anton: Metall. Trans. A, 1985, vol. 16A, pp. 1997-2005.

56. K.E. Yoon, R.D. Noebe, and D.N. Seidman: Acta Mater., 2007, vol. 55, pp. 1159-69.

57. C.L. Fu, R. Reed, A. Janotti, and M. Krcmar: Superalloys 2004, TMS, Warrendale, PA, 2004, pp. 867-76.

58. A. Janotti, M. Krčmar, C.L. Fu, and R.C. Reed: Phys. Rev. Lett., 2004, vol. 92, p. 085901. 